\title{
Impact of Pulse Voltage as Desulfator to Improve Automotive Lead Acid Battery Capacity
}

\author{
EL MEHDI LAADISSI \\ Laboratory LM2PI, ENSET, \\ Mohamed V University \\ Rabat, Morocco
}

\author{
ANAS EL FILALI \\ Laboratory LM2PI, ENSET, \\ Mohamed V University \\ Rabat, Morocco
}

\author{
MALIKA ZAZI \\ Laboratory LM2PI, ENSET, \\ Mohamed V University \\ Rabat, Morocco
}

\begin{abstract}
This paper studies the impact of Pulse Voltage as Desulfator to recover weak automotive Lead Acid Battery capacity which is caused by Sulfation. This technique is used to overcome the premature loss of battery capacity and speed up the process of charging and extend the lead acid battery life cycle 3 to 4 times compared with traditional charging methods using constant current. Sulfation represents the accumulation of lead sulfate on the electrodes (lead plates). This phenomenon appears naturally at each discharge of the battery, and disappears during a recharge. This is common with starter batteries in cars driven in the city with a load-hungry accessory. A motor in idle or at low speed cannot charge the battery sufficiently. Voltage pulse decompose the sulfate (PbSO4) attached to the electrode which is the main cause of the loss of capacity. In this paper, we study the effects of the recovery capacity of a Lead Acid Battery. Voltage pulses will be applied on a commercial automotive battery to collect data, using a charger/Desulfator prototype based on a PCDUINO. The experiment results show that there is improvement of Cold Cranking Amps level, and charge time duration of the Lead Acid Battery after using our prototype.
\end{abstract}

Keywords-Lead acid battery; desulfator; pulse charging; cold cranking; sulfation

\section{INTRODUCTION}

In the last few years there has been a growing interest in batteries, they have revolutionized the way of storing electrical energy. Its use is widespread and growing, it helps to have a reserve of electrical energy autonomous and mobile cell phones, photovoltaic systems, space equipment, laptops and other devices to public or industrial use. Especially since the battery is a power source that can partially replace the use of internal combustion systems used in the new generation of hybrid electric cars and this to reduce the emission of greenhouse gases which is now the major concern of humanity. To use a battery effectively, it is necessary to understand its dynamics and discover the parameters which may affect its performance. The problem with these types of batteries is that they need to maintain their useful life capacity as long as possible and to optimize the use of their energy [1], [2].

\begin{tabular}{|ll|}
\hline \multicolumn{2}{|l|}{ Nomenclatures } \\
$\mathrm{PbSO} 4$ & Lead(II) Sulfate \\
$\mathrm{H} 2 \mathrm{SO} 4$ & Sulfuric Acid \\
$\mathrm{Pb}$ & Lead \\
$\mathrm{PbO} 2$ & Lead dioxide \\
& \\
Abbreviations \\
$\mathrm{PWM}$ & Pulse-Width Modulation \\
LAB & Lead Acid Battery \\
$\mathrm{SLI}$ & Start, Lighting, Ignition \\
$\mathrm{CCA}$ & Cold Cranking APMS \\
DOD & Depth of Discharge \\
\hline
\end{tabular}

A. Research Purposes

The purpose of this study is:

- To examine the effect of a recovery made from lead acid battery capacity using a pulse voltage charging method on a battery that has a low storage capacity.

- Verify and validate the circuit prototype producing voltage pulses that have been made previously.

\section{B. Problem Formulation}

How the method of "charge pulse" helps lead acid batteries to recover their capacity, what is the effect of these "impulsions" on batteries. To do so, we will take an interest in the value of power starter/cold cranking amps and the duration of charging a lead acid battery.

\section{Scope of the Experiment}

Study was conducted using commercial automotive batteries on the market. The charging process is done by using our prototype charger based on PCDUINO shown in Fig. 1 and an algorithm programmed with python language. 


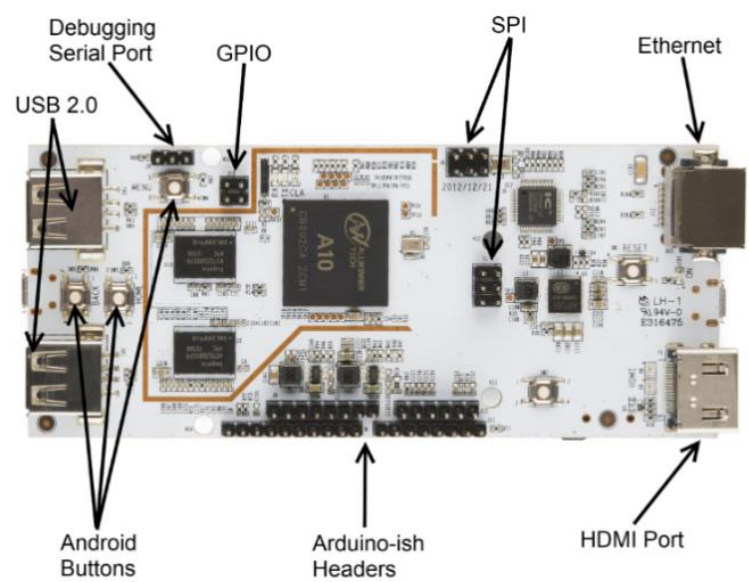

Fig. 1. Desulfator programmable main board.

\section{THEORETICAL FRAMEWORK}

\section{A. Charging Process of a Lead Acid Battery}

Lead acid battery have anode made of lead $(\mathrm{Pb})$ and the cathode made from lead dioxide ( $\mathrm{PbO} 2), \mathrm{H} 2 \mathrm{SO} 4$, and a separator between the two electrodes. The chemical reaction that occurs at the positive electrode and negative electrode of the battery are as follows [3]:

$$
\underset{\substack{\text { positive } \\
\text { plate }}}{\mathrm{PbO}_{2}}+\underset{\begin{array}{l}
\text { negative } \\
\text { plate }
\end{array}}{\mathrm{Pb}}+2 \mathrm{H}_{2} \mathrm{SO}_{4} \underset{\text { charge }}{\stackrel{\text { discharge }}{\rightleftarrows}} 2 \mathrm{PbSO}_{4}+\mathrm{H}_{2} \mathrm{O}
$$

\section{B. Sulfation}

Sulfation represents the accumulation of lead sulfate on the electrodes. This phenomenon arises naturally in every discharge of the battery [4]-[6], and disappears when a refill. However, under certain conditions (too deep or prolonged discharge, large temperature, gasification of the electrolyte), plates of stable lead sulfate appear and are not dissolved during charging. Lead sulfate thus generated decreases battery capacity by preventing the reactions on the electrode and its low electrical conductivity.

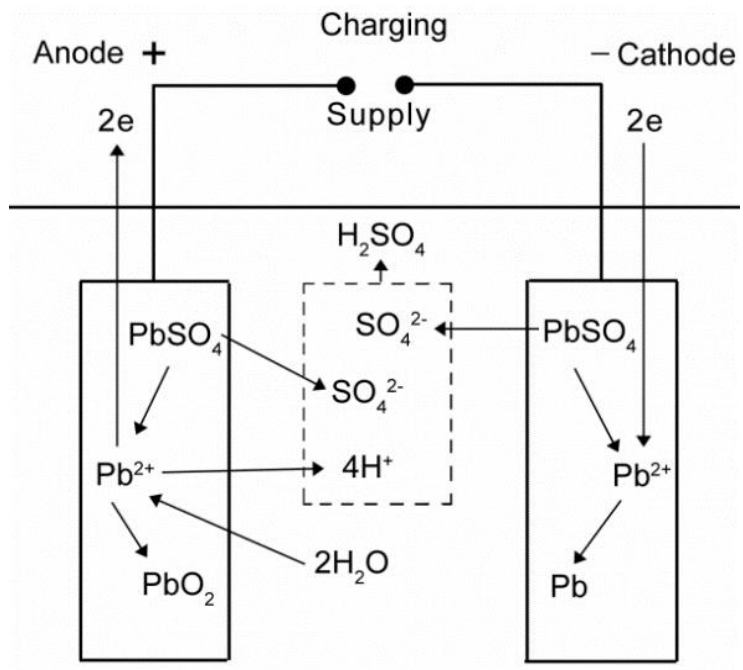

Fig. 2. Construction of a lead acid battery.
Based on the above reaction $\mathrm{PbSO} 4$ will be formed at the positive electrode and negative electrode during charging or using the battery while in the process of charging the electrode $\mathrm{PbSO} 4$ will decompose and become $\mathrm{Pb}, \mathrm{PbO} 2$ and $\mathrm{H} 2 \mathrm{SO} 4$ [7]. Lead acid battery construction can be seen in Fig. 2.

\section{Desulfation}

There is a way to reverse the sulfation process of a battery. This consists of sending electrical pulses to the battery with a resonance frequency (between 2 and $6 \mathrm{MHz}$ ). During this process, the sulfur ions collide with the plates, which have the effect of dissolving lead sulfate covering them. The shape of the voltage pulse can be seen in Fig. 3 .

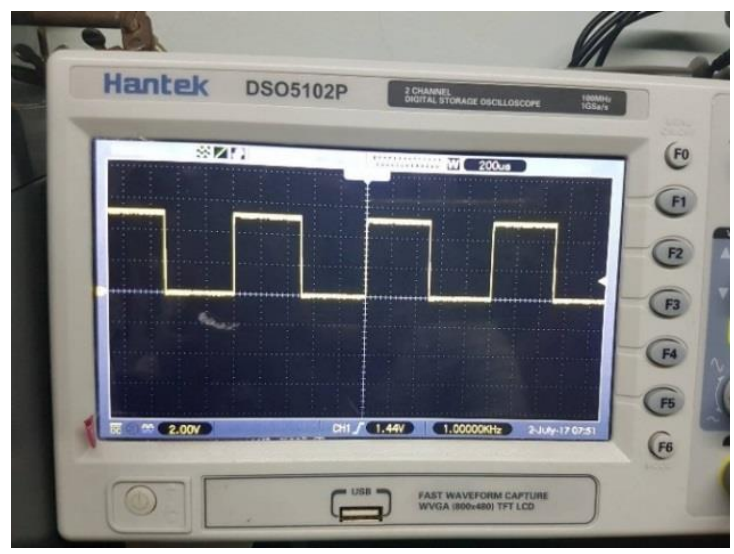

Fig. 3. Output pulse shape.

\section{Lead Acid Battery Capacity and Peukert Law}

Understanding battery capacity refers to the amount of energy that can be stored. Lead acid battery manufacturers often use the specification known as Amp Hour to provide an indication of the stored battery capacity. But lead acid battery capacity will be determined by the amount of load current. This means that greater the load on the battery, the less realized capacity you will have. This phenomenon is called Peukert law [8].

\section{E. Lead Acid Battery Types}

Based on the application, the LAB can be divided into several types [9]:

- SLI (Start, Lighting, Ignition) which is used in automotive.

- Stationary to support the power supply to generate and store electrical energy used in telecommunications systems, electric utilities centre, and computer systems.

- Traction, to power transportation equipment such as forklifts, electric cars, and mining equipment.

- Battery specially meant for the use of aircraft, submarines and military equipment.

\section{F. Starter Power}

World power industry uses standard automotive starter with a size of Cold Cranking APMS (CCA). The number indicates the current in ampere that the battery can deliver at $18^{\circ} \mathrm{C}\left(0^{\circ} \mathrm{F}\right)$ for 30 seconds, while being able to provide a 
voltage of 1.2 volts per cell or higher. American and European norms differ slightly.

\section{G. Depth of Discharge}

Depth of Discharge (DOD) is used to describe how deeply the battery is discharged. If we say a battery is $100 \%$ fully charged, it means the DOD of this battery is $0 \%$, If we say the battery have delivered $40 \%$ of its energy, here are $60 \%$ energy reserved, we say the DOD of this battery is $40 \%$. And if a battery is $100 \%$ empty, the DOD of this battery is $100 \%$. DOD always can be treated as how much energy that the battery delivered.

\section{RESEARCH METHODS}

\section{A. Stages of Research}

Flowchart of this research can be seen in Fig. 4. The research began with a literature study, followed by the preparation of the batteries to be tested. Battery preparation is intended to obtain a battery which has a weak storage capacity, so that we can see the effects of the voltage pulse charging technique on the capacity of the lead acid battery. Battery preparation is done by charging with a constant current for 30 cycles. After the battery is ready, treatment is initiated by the load voltage impulsion, respecting the manufacturer's specifications. Throughout the charge cycle the battery data are collected and stored to analyse the effects of this voltage pulses on the capacity of the lead acid battery.

\section{B. Data and Sources}

Data:

1) Results of voltage measurement.

2) The capacity and time.

3) Battery power starter.

Sources:

1) Instruments measurement of capacity.

2) Battery manufacturer specifications.

\section{RESULTS AND DISCUSSION}

\section{A. Battery Preparation}

The lead acid battery used were NS60, that has been used for 4-6 months on the vehicle, with the condition Voltage 12,29 Volt, 195 CCA starter power, according to standards Issued by Yuasa, NS60 starter has a standard power of 325 CCA. ${ }^{1}$

Aside from the value of the starter power of the lead acid battery, capacity can also be seen through the value of the voltage, a battery which has a value voltage of $12.65 \mathrm{~V}$ is said to have a capacity of $100 \%, 12.40 \mathrm{~V}$ is said to have a capacity of $75 \%$ [10]-[13].

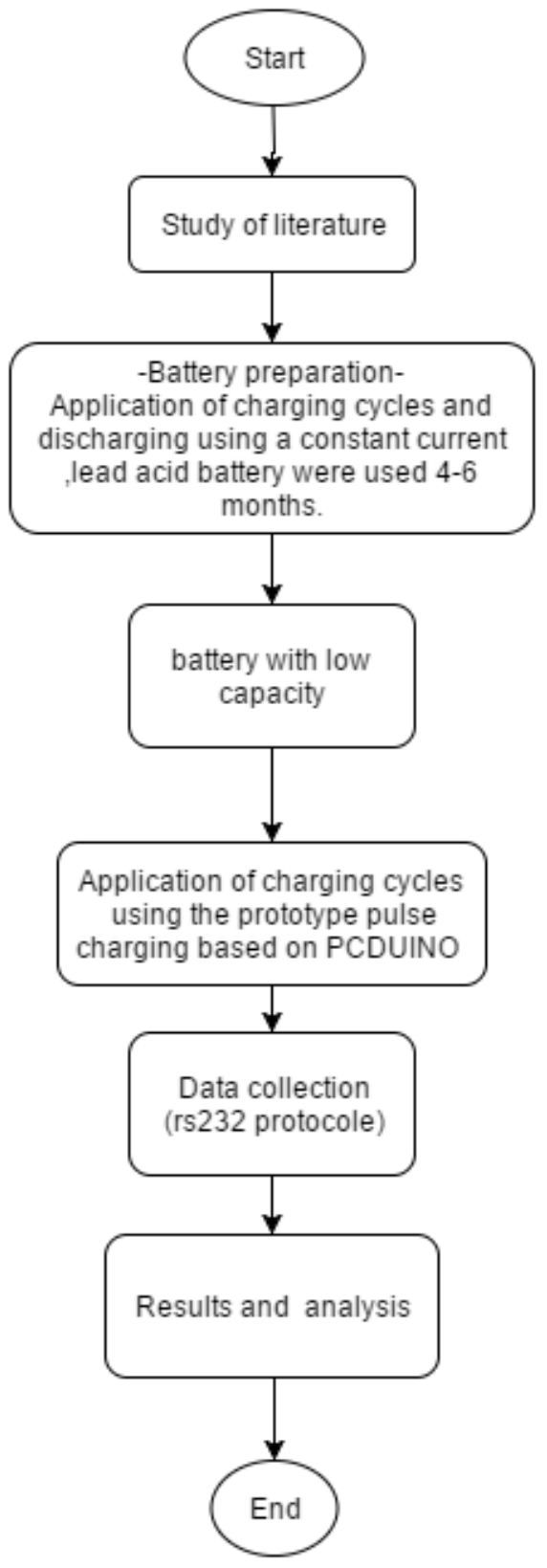

Fig. 4. Stages of research.

\section{B. Experiment and Data Collection}

The lead acid battery that has been used is measured by Battery Analyzer BT 747 DHC, to know the initial conditions of power starter / battery capacity. Furthermore, we charge the measured battery with shock pulses with a frequency between $2 \mathrm{kHz}$ and $6 \mathrm{MHz}$, the frequency is selected by the user through a menu programmed in the PCDUINO until the voltage reaches $13.5 \mathrm{~V}$. 
After that, the battery rested for 60 minutes to obtain a stable voltage to subsequently remeasure Battery Analyzer to determine the value of starter of the battery, then discharged for 60 minutes. The cycle is carried out repeatedly for 20 cycles so that the change in the value of Starter CCA each cycle of charging and discharging can be known. Circuit producing a voltage pulse can be seen in Fig. 5 and 6 while the shape of the pulses generated can be seen in Fig. 3.

\section{Pulse Voltage Effect on the Battery Capacity}

A major increase can clearly be seen in the value of the "CCA" during the first cycles. While in the subsequent cycles we see an increase that was not significant Fig. 7. While Fig. 8 shows an increase in voltage on the lead acid battery.

\section{Influence of the Charging Cycles on the Charging Time}

For the first cycles, we needed a large amount of time to obtain the required voltage $13.5 \mathrm{~V}$ but faster one reaches this value for subsequent cycles. This is due to the value of the internal resistance of the battery which is caused by sulfation.

With the passage of the charging cycle, lead sulfate decreases so that the charging process becomes faster. Thus, the battery regains the ability to store an electric charge. In addition, it time to full charge is visually improved.

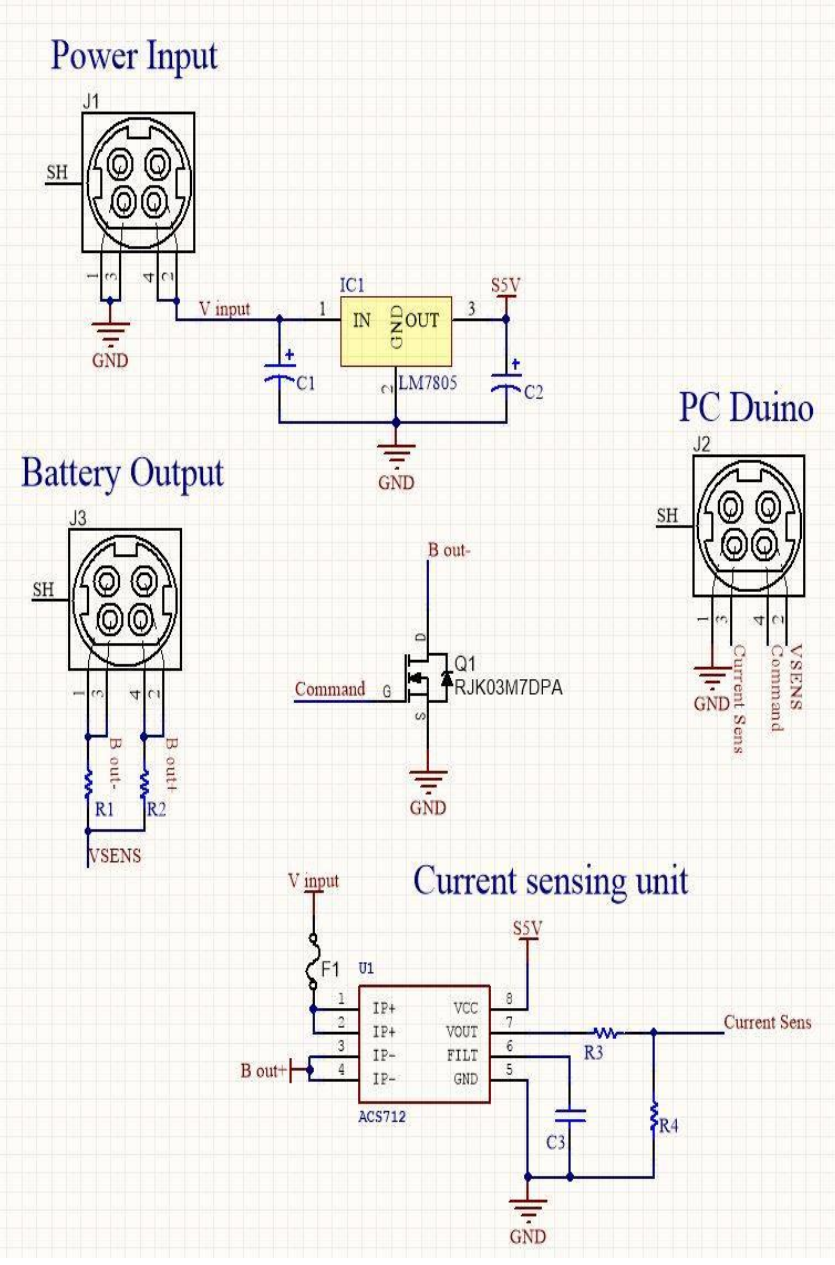

Fig. 5. Circuit voltage Pulse generator.

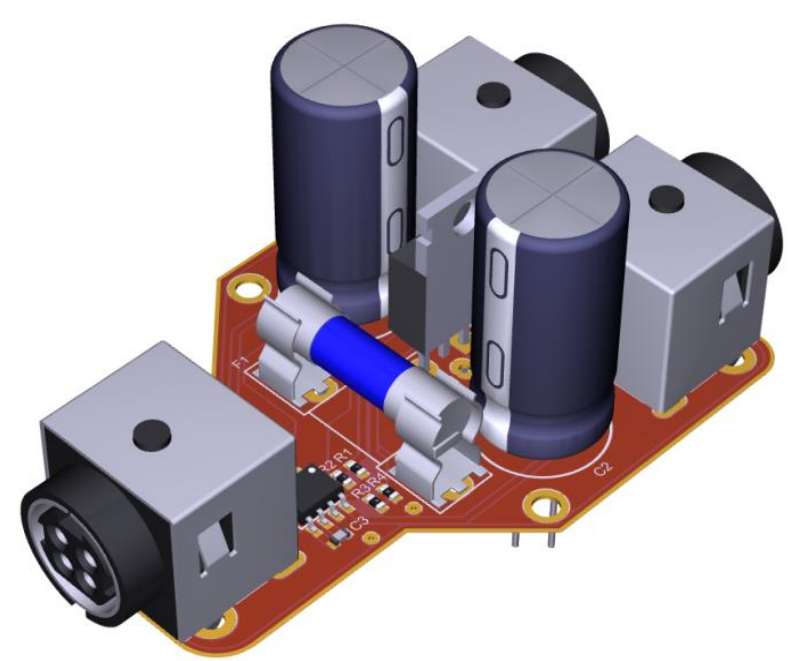

Fig. 6. 3D view of the pulse voltage generator.

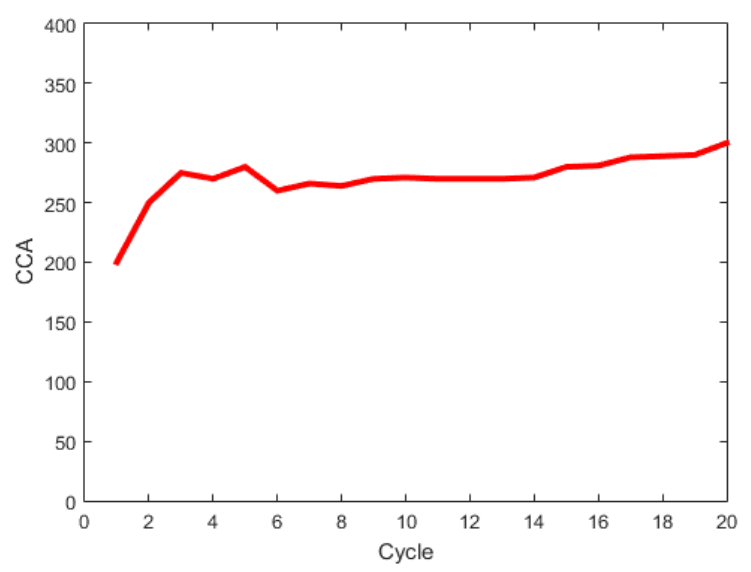

Fig. 7. Evolution of the CCA value.

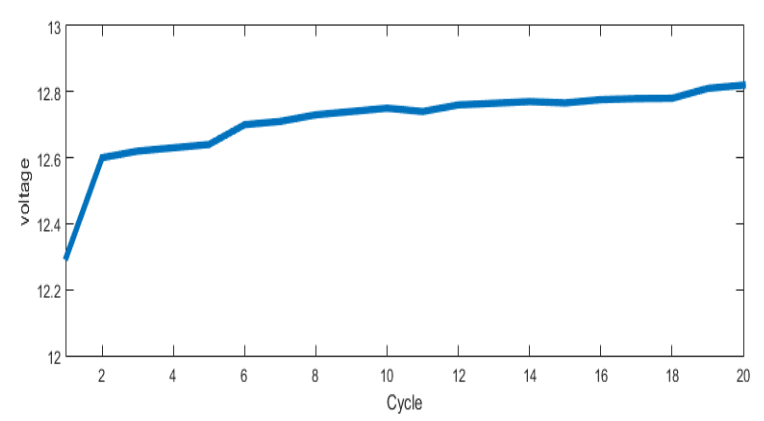

Fig. 8. Voltage value after each charge-discharge cycle.

\section{CONCLUSIONS}

Based on the above experimental results, charging the lead acid battery with the generated voltage pulses will increase storage capacity, the battery will be getting better after charging and discharging cycles.

At the beginning, the cycle of the charging process will take longer because of the high value of internal resistance which is due to sulfation, but with the declining value of the 
internal resistance the lead acid battery storage capacity will be recovered and the charging time will be shorter. The prototype generates a voltage pulse that can increase battery capacity.

The use of voltage pulse charging technology is a highly promising method to be applied to batteries made from lead sulfate to extend the service life of the lead acid battery, other than that, it would be good to reduce the environmental pollution caused by the lead acid battery waste.

\section{REFERENCES}

[1] D. Berndt, Maintenance-Free Batteries, second ed., Wiley, New York, 1997, p. 453.

[2] Spanos, C., Berlinger, S. A., Jayan, A., \& West, A. C. (2016). Inverse charging techniques for sulfation reversal in flooded lead-acid batteries. Journal of The Electrochemical Society, 163(8), A1612-A1618

[3] Kujundžić, G., Ileš, Š., Matuško, J., \& Vašak, M. (2017). Optimal charging of valve-regulated lead-acid batteries based on model predictive control. Applied Energy, 187, 189-202.

[4] P. Ruetschi, J. Power Sources, 127 p. 33-44, 2004.G. Eason, B. Noble,

[5] H. Ikeda, S. Minami, Song JieHou, Y. Onishi, A Kozawa.J. Asian Electric Vehicle, 3, p. 683, 2005.
[6] B. Culpin, A.F. Hollenkamp, D.A, J. Rand,J . Power Sources, 38, p.6374. 1992.

[7] C.V. D'Alkaine, L.M.M. De Souza, P.R. Impinnisi.J. Power Sources, 158, p. 997, 2006.

[8] Cugnet, M.G.; Dubarry, M.; Liaw, B.Y. Peukert's law of a lead-acid battery simulated by a mathematical model. ECS Trans. 2010, 25, $223-$ 233.

[9] E. Rocca, J. Steinmetz, S. Weber, Mechanism of formation of dense anodic films of $\mathrm{PbO}$ on lead and lead alloys in sulfuric acid, J. Electrochem. Soc. 146 (1999) 54-58. M. Young, The Technical Writer's Handbook. Mill Valley, CA: University Science, 1989.

[10] P. Rüetschi, B.D. Cahan, Anodic corrosion and hydrogen and oxygen overvoltage on lead and lead-antimony alloys, J. Electrochem. Soc. 104 (1957) 406-413.

[11] S. Atlung, B. Zachau-Christiansen, Degradation of the positive plate of the lead-acid battery during cycling, J. Power Sources 30 (1990) 131141.

[12] J. Alzieu, N. Koechlin, J. Robert, Internal stress variations in lead-acid batteries during cycling, J. Electrochem. Soc. 134 (1987) 1881-1884.

[13] Laadissi El, El Filali A., \& Zazi, M (2016). Nonlinear Black Box Modeling Of A Lead Acid Battery Using Hammerstein-Wiener Model. Journal of Theoretical and Applied Information Technology, 89(2), 476. 